\title{
The value of high-resolution computed tomography (HRCT) to determine exercise ventilatory inefficiency and dynamic hyperinflation in adult patients with cystic fibrosis
}

Ernesto Crisafulli ${ }^{1 *}$ D, Elisabetta Teopompi ${ }^{1}$, Silvia Luceri ${ }^{2}$, Francesco Longo ${ }^{1,3}$, Panagiota Tzani ${ }^{1}$, Paolo Pagano ${ }^{2}$, Antonella lelpo ${ }^{1}$, Chiara Longo ${ }^{1}$, Marcello Di Paolo ${ }^{4}$, Nicola Sverzellati $^{2}$, Paolo Palange ${ }^{4}$, Alfredo Chetta ${ }^{1}$ and Giovanna Pisi ${ }^{3}$

\begin{abstract}
Introduction: In Cystic Fibrosis (CF), exercise ventilatory inefficiency and dynamic hyperinflation (DH) cause exercise limitation and induce poor exercise tolerance. High-resolution computed tomography (HRCT) of the lung can detect pulmonary abnormalities in CF patients. We aimed to identify the determinants of exercise ventilatory inefficiency and DH using HRCT-derived metrics.

Methods: Fifty-two adult CF patients were prospectively enrolled; all participants underwent cardio-pulmonary exercise test (CPET) and HRCT. Radiological impairment was evaluated by the Brody II scoring system. Slope and intercept of the minute ventilation $/ \mathrm{CO}_{2}$ production $\left(V^{\prime}{ }^{\prime} N^{\prime}{ }_{\mathrm{CO} 2}\right)$ regression line and the ratio of inspiratory capacity/ total lung capacity (IC/TLC) at rest and at peak of exercise were measured.
\end{abstract}

Results: Four groups of patients were identified based on the combination of ventilatory efficiency (Vef) or inefficiency (Vin) and the presence/absence of DH. Compared to other groups, CF adults with Vin and DH had worse functional status and higher total (T), bronchiectasis (B) and air trapping (AT) scores at HRCT. Significant correlations were found between $V_{E}^{\prime} N^{\prime} \mathrm{CO}$ intercept and $V_{E}^{\prime} N^{\prime}{ }_{C O 2}$ slope $(\rho-0.455, p=0.001)$ and between $V_{E}^{\prime} N^{\prime}{ }_{C O 2}$ intercept and $\Delta$ inspiratory capacity (IC) $(\rho-0.334, p=0.015)$. Regression analysis identified AT score (cut-off 7.9, odds ratio-OR 3.50) as the only independent predictor of Vin and T (cut-off 53.6, OR 4.98), B (cut-off 16.1, OR 4.88), airways wall thickening (AWT) (cut-off 13, OR 3.41), and mucous plugging (MP) scores (cut-off 11.7, OR 4.18) as significant predictors of $\mathrm{DH}$.

Conclusion: In adult CF cohort, values of HRCT metrics are determinants of Vin (AT) and DH (T, B, AWT, MP).

Keywords: Cystic fibrosis, Ventilatory inefficiency, Dynamic hyperinflation, Brody II score

\footnotetext{
*Correspondence: ernesto.crisafulli@unipr.it

'Department of Medicine and Surgery, Respiratory Disease and Lung

Function Unit, University of Parma, Via Rasori 10, 43126 Parma, Italy

Full list of author information is available at the end of the article
}

(c) The Author(s). 2019 Open Access This article is distributed under the terms of the Creative Commons Attribution 4.0 International License (http://creativecommons.org/licenses/by/4.0/), which permits unrestricted use, distribution, and reproduction in any medium, provided you give appropriate credit to the original author(s) and the source, provide a link to the Creative Commons license, and indicate if changes were made. The Creative Commons Public Domain Dedication waiver (http://creativecommons.org/publicdomain/zero/1.0/) applies to the data made available in this article, unless otherwise stated. 


\section{Introduction}

In Cystic Fibrosis (CF) patients, pulmonary infections lead to a progressive decline in lung function [1]. Although spirometry and, particularly, the forced expiratory volume at 1 st second $\left(\mathrm{FEV}_{1}\right)$ is considered a valuable measure for lung function monitoring [2], variables derived from exercise testing, such as the cardio-pulmonary exercise test (CPET), are more sensitive than spirometry in detecting early structural pulmonary changes in CF patients [3].

In adolescents with $\mathrm{CF}$, an exaggerated ventilatory response to exercise but adequate to $\mathrm{V}^{\prime} \mathrm{CO}_{2}$ (normal $\mathrm{V}_{\mathrm{E}}$ / $\mathrm{V}^{\prime} \mathrm{CO} 2$ slope) was documented [4] and, interestingly, in adult $\mathrm{CF}$ patients the $\mathrm{V}_{\mathrm{E}}{ }_{\mathrm{E}} / \mathrm{V}^{\prime}{ }_{\mathrm{CO} 2}$ at peak of exercise was an independent determinant of exercise limitation, especially in those with a worse lung function [5]. Moreover, in adults with $\mathrm{CF}$, a high prevalence of exercise dynamic hyperinflation $(\mathrm{DH})$ was found, secondary to the development of air trapping during exercise; $\mathrm{DH}$ was also shown to be associated to poor resting lung function, reduced exercise tolerance and increased exertional dyspnea [6].

High-resolution computed tomography (HRCT) of the lung is able to demonstrate a broad range of pulmonary abnormalities in CF patients with mild-to-moderate lung disease [7], identifying lower airway inflammation and early lung impairments [8]. The Brody score [7] is a composite HRCT score including different radiological features of lung disease (Bronchiectasis-B, Airways Wall Thickening-AWT, Mucous plugging-MP, Parenchyma-P and Air Trapping-AT) and demonstrating a high inter-observer reproducibility [9]. In CF patients, higher Brody scores indicate more severe disease [7]; they are also strongly associated with lung disease progression [10], predicting the rate of pulmonary exacerbations up to 10 -year follow-up [11].

Interestingly, with regards to the relationship between HRCT-derived variables and the ventilatory response to exercise, the emphysema HRCT metrics were independent predictors of exercise-induced $\mathrm{DH}$ and $\mathrm{V}_{\mathrm{E}}^{\prime} / \mathrm{V}^{\prime}{ }_{\mathrm{CO} 2}$ slope in COPD patients [12]. In CF adults, however, no studies assessed the value of the variables derived from HRCT to determine both the exercise ventilatory response to $\mathrm{CO}_{2}$ and $\mathrm{DH}$. Therefore, we aimed to identify in a large cohort of adult patients with CF the determinants of exercise ventilatory response to $\mathrm{CO}_{2}$ and $\mathrm{DH}$ using HRCT-derived metrics, as expressed by the Brody II score.

\section{Methods}

\section{Patients}

We conducted this prospective study at the University Hospital of Parma (Italy) between June 2013 and July 2017. The main inclusion criteria were a confirmed diagnosis of $\mathrm{CF}$ as recommended by international guidelines [13], age $>18$ years and a stable respiratory condition (i.e. patients free from exacerbations) for at least 4 weeks before enrolment Patients with lung transplant, pregnancy and concomitant malignancies or comorbidities (i.e. heart failure, previous rib fracture) which could preclude their safety were excluded.

The study was conducted according to the Declaration of Helsinki; all the procedures and their risks were explained to the patients, who gave their written informed consent for the participation to the study. The ethical committee of the University Hospital of Parma approved the protocol (approval number: 200084; 07 June 2013). All participants' data were anonymously analyzed and reported. No extramural funding was used to support the study.

\section{Measurements}

For all patients, anthropometric characteristics (age, gender, body mass index-BMI and fat-free mass index-FFMI), presence of diabetes, CFTR mutations (F508del/F508del, F508del/Other, or Other/Other), Pseudomonas aeruginosa colonization, long-term oxygen therapy and domiciliary non-invasive mechanical ventilation were recorded at the enrolment. BMI was calculated in kilograms per square meter. Body composition was also assessed by a foot-to-foot bioelectrical impedance analysis (BIA) method by a body composition analyzer (model SC-331S, Tanita, Tokyo, Japan). The fat-free mass (FFM) was standardized for height to calculate the FFM index (FFMI = FFM/height squared, in kilograms per square meter).

All lung function tests were performed according to the international recommendations [14]. A flow-sensing spirometer and a body plethysmograph connected to a computer for data analysis (Vmax 22 and 6200, Sensor Medics, Yorba Linda, USA) were used for the measurements. $\mathrm{FEV}_{1}$ and forced vital capacity (FVC) were recorded; the $\mathrm{FEV}_{1} / \mathrm{FVC}$ ratio was considered as the index of airflow obstruction. Thoracic gas volume (TGV) was measured by body plethysmography with the patients painting against a closed shutter at a frequency slightly $<1 \mathrm{~Hz}$ and supporting their cheeks with their hands. Total lung capacity (TLC) was obtained as the sum of TGV and related inspiratory capacity (IC). To ensure reproducibility for each spirometry and lung volume variables at least three measurements were taken; the highest value was considered. The flow-sensor was calibrated before each test using a three-liter syringe. $\mathrm{FEV}_{1}$, $\mathrm{FVC}$, and IC were expressed as a percentage of the predicted values [15].

Incremental CPET was performed according to the standardized international procedure [16]. Patients were not pre-treated with $\beta_{2}$ agonists before testing, but they 
could take their current therapies. After calibrating the oxygen and carbon dioxide analysers and flow mass sensor, patients were invited to sit on an electromagnetically braked cycle ergometer (Corival PB, Lobe Bv, Groningen, The Netherlands) and the saddle was adjusted properly to avoid the maximal extension of the knee. The exercise protocol involved an initial rest of $3 \mathrm{~min}$, followed by unloaded cycling for another $3 \mathrm{~min}$ with an increment of 5 to 15 watts every minute, according to the patient's anthropometry and degree of functional impairment, in order to achieve an exercise time between 8 and $12 \mathrm{~min}$. Patients were invited to maintain a pedalling frequency of 60 rates per minute.

Breath-by-breath oxygen uptake $\left(\mathrm{V}_{\mathrm{O} 2}^{\prime}\right.$ in $\left.\mathrm{L} / \mathrm{min}\right)$, carbon dioxide production $\left(\mathrm{V}_{\mathrm{CO} 2}^{\prime}\right.$ in $\mathrm{L} / \mathrm{min}$ ), tidal volume $\left(\mathrm{V}_{\mathrm{T}}\right.$ in $\left.\mathrm{L}\right)$ and minute ventilation $\left(\mathrm{V}_{\mathrm{E}}^{\prime}\right.$ in $\left.\mathrm{L} / \mathrm{min}\right)$ were recorded during the test (CPX/D; Med Graphics, St Paul, MN, USA). Patients were continuously monitored with a 12-lead electrocardiogram (Welch Allyn CardioPerfect, Delft, the Netherlands) and a pulse oximeter (Pulse Oximeter 8600, Nonin Medical Inc., MPLS, Mn U.S.A.). Blood pressure was measured every two minutes. Stopping criteria consisted of symptoms, such as unsustainable dyspnea, leg fatigue or chest pain, a significant ST-segment depression at ECG, or a drop in systolic blood pressure or oxygen saturation $\leq 84 \%$ [17].

Workload and $\mathrm{V}^{\prime} \mathrm{O} 2$ at peak were recorded as the mean value of watts and $\mathrm{V}_{\mathrm{O} 2}^{\prime}$ during the last $20 \mathrm{~s}$ of the test. $\mathrm{V}^{\prime}{ }_{\mathrm{O} 2}$ at peak was expressed as $\mathrm{mL} / \mathrm{kg} / \mathrm{min}$. The ventilatory response during exercise was expressed as a linear regression function by plotting $\mathrm{V}_{\mathrm{E}}^{\prime}$ against $\mathrm{V}_{\mathrm{CO} 2}^{\prime}$ obtained every $10 \mathrm{~s}$, excluding data above the ventilatory compensation point [17]. Then, the slope and $\mathrm{Y}$ intercept values were obtained from the $\mathrm{V}_{\mathrm{E}} / \mathrm{V}^{\prime}{ }_{\mathrm{CO} 2}$ regression line. $\mathrm{V}_{\mathrm{E}}^{\prime} / \mathrm{V}_{\mathrm{CO} 2}^{\prime}$ at rest, $\mathrm{V}_{\mathrm{E}}^{\prime} / \mathrm{V}_{\mathrm{CO} 2}^{\prime}$ slope and $\mathrm{V}_{\mathrm{E}}^{\prime} / \mathrm{V}_{\mathrm{CO} 2}^{\prime}$ intercept $\left(\mathrm{L} \cdot \mathrm{min}^{-1}\right)$ were recorded. Values of $\mathrm{V}_{\mathrm{E}}^{\prime} / \mathrm{V}^{\prime} \mathrm{CO} 2$ slope $\geq$ 30 and $<30$, derived from the median value in our cohort, were used to define patients with an exercise ventilatory inefficiency (Vin) and patients with ventilatory efficiency (Vef), respectively [18].

The end-tidal pressure of $\mathrm{CO}_{2}\left(\mathrm{P}_{\mathrm{ETCO} 2}\right.$, in $\left.\mathrm{mm} \mathrm{Hg}\right)$ was measured as the mean of $\mathrm{P}_{\mathrm{ETCO} 2}$ during the 3-min rest period and during the last $20 \mathrm{~s}$ of the test; moreover, the difference between $\mathrm{P}_{\mathrm{ETCO} 2}$ at peak and $\mathrm{P}_{\mathrm{ETCO} 2}$ at rest $\left(\triangle \mathrm{P}_{\mathrm{ETCO} 2}\right)$ was recorded.

Changes in operational lung volumes were assessed every two minutes during exercise and at peak exercise, taking the IC measured at rest, as the baseline. After a full explanation of the procedure, satisfactory technique and reproducibility of IC maneuvers were established during an initial practice session at rest. Assuming that TLC remains constant during exercise [19], a change in IC $(\Delta$ IC, $\mathrm{L}) \leq-0.100 \mathrm{~L}$ at peak of exercise was considered to define patients with $\mathrm{DH}$, as reported from the literature [20].

The cardiovascular response to exercise was expressed by the following parameters: oxygen pulse $\left(\mathrm{O}_{2}\right.$ pulse $)$, $\mathrm{HR}$ recovery and double product (DP) reserve. $\mathrm{O}_{2}$ pulse (in $\mathrm{mL} /$ beats/min) was calculated by dividing instantaneous $\mathrm{V}_{\mathrm{O} 2}$ by the $\mathrm{HR}$ and was recorded at rest and as the change between the peak of exercise and the resting phase $\left(\Delta \mathrm{O}_{2}\right.$ pulse) [17]. $\mathrm{HR}$ recovery (in beats) was defined as the reduction of the $\mathrm{HR}$ at the peak exercise level compared to the HR after one minute of the exercise cessation [17]. DP (mmHg*bpm) at rest and at maximal exercise was calculated by the product of systolic blood pressure and HR [21]; DP reserve was calculated as DP at maximal exercise minus DP at rest and was also expressed as a ratio to workload in watts.

Oxygen saturation $\left(\mathrm{SpO}_{2}\right)$ was reported at rest and as the difference between values at peak of exercise and at rest $\left(\Delta \mathrm{SpO}_{2}\right)$. Peak dyspnea and fatigue were described as visual analogic scale (VAS) with 0-100 score and then divided by peak workload (watts) for analysis.

Patients were scanned with a 128-slice Somatom Definition Flash scanner (Siemens Medical Solutions, Forchheim, Germany). Technical parameters were as follows: volumetric acquisition, collimation $128 \times 2 \times 0.6$ $\mathrm{mm} ; 1 \mathrm{~mm}$ slice thickness, rotation time $0.28 \mathrm{msec}$; tube voltage $80-100 \mathrm{kVp}$; tube current modulation (CareDose) on. Images were visually scored using a window setting $(-1550 \mathrm{~W},-600 \mathrm{~L})$. Each HRCT scan was evaluated independently by two radiologists (S.L. and P.P.), both with a 3-year imaging experience. Readers scored HRCTs using the Brody II scoring system [7]. The total score $(\mathrm{T})$ is the sum of the following sub-scores: Bronchiectasis-B, Airways Wall Thickening-AWT, Mucous Plugging-MP, Parenchyma-P (e.g. bullae, ground glass and consolidation) and Air Trapping-AT with decreased attenuation areas. Each of the five sub-scores is rated according to presence and severity, in each of the six lobes, lingula being considered as a separate lobe. All scores and sub-scores are expressed as a percentage of the maximum possible score, ranging from 0 (no pathological findings) to 100 (maximum severity).

\section{Statistical analysis}

Analyses were performed with IBM SPSS Statistics 25.0 (Armonk, New York, USA) and Shapiro-Wilk test was used to assess the normality of distribution. Data were reported as medians (1st quartile; 3rd quartile) for continuous variables with non-normal distribution or means \pm standard deviation (SD) for those with normal distribution. Number of patients (\%) was used for categorical variables. Comparison analysis were performed using the chi-square $\left(X^{2}\right)$ or the Fisher exact test for categorical variables and the $t$ test or the nonparametric Mann-Whitney 
Table 1 General characteristics according to the ventilatory efficiency and dynamic hyperinflation

\begin{tabular}{|c|c|c|c|c|c|c|}
\hline Variables & $\begin{array}{l}\text { Study } \\
\text { sample } n \\
=52\end{array}$ & $\begin{array}{l}\text { Patients with Vef and } \\
\text { without } \mathrm{DH} n=10 \text { (19\%) }\end{array}$ & $\begin{array}{l}\text { Patients with Vin and } \\
\text { without } \mathrm{DH} n=13 \text { (25\%) }\end{array}$ & $\begin{array}{l}\text { Patients with Vef and } \\
\text { with } \mathrm{DH} n=14(27 \%)\end{array}$ & $\begin{array}{l}\text { Patients with Vin and } \\
\text { with } \mathrm{DH} n=15 \text { (29\%) }\end{array}$ & $\begin{array}{l}p \\
\text { value } \\
a\end{array}$ \\
\hline Age, years & $29.1 \pm 8.1$ & $30.9 \pm 10.1$ & $29.8 \pm 8$ & $26.3 \pm 6$ & $30 \pm 8.7$ & 0.494 \\
\hline Male, \% & 58 & 80 & 46 & 50 & 60 & 0.373 \\
\hline $\mathrm{BMl}, \mathrm{kg} / \mathrm{m}^{2}$ & $\begin{array}{l}21.4[19.5 ; \\
22.5]\end{array}$ & $22.3[21.7 ; 24.3]$ & $20.8[19 ; 22.8]$ & $20.9[19.8 ; 21.9]$ & $20.9[18.8 ; 23.3]$ & 0.230 \\
\hline $\mathrm{FFMl}, \mathrm{kg} / \mathrm{m}^{2}$ & $\begin{array}{l}17.1[15.4 ; \\
18]\end{array}$ & $17.6[15.7 ; 18.3]$ & $16.4[14.5 ; 17.4]$ & $17[15.6 ; 18.2]$ & $17.4[15.3 ; 18]$ & 0.402 \\
\hline Diabetes, $\%$ & 31 & 50 & 23 & 29 & 27 & 0.523 \\
\hline CFTR mutations, \% & & & & & & 0.972 \\
\hline F508del/F508del & 42 & 40 & 39 & 36 & 54 & \\
\hline F508del/Other & 41 & 40 & 46 & 43 & 33 & \\
\hline Other/Other & 17 & 20 & 15 & 21 & 13 & \\
\hline $\begin{array}{l}\text { Pseudomonas } \\
\text { aeruginosa } \\
\text { colonization, \% }\end{array}$ & 94 & 80 & 92 & 100 & 100 & 0.133 \\
\hline LTOT, \% & 8 & 0 & 0 & 14 & 13 & 0.328 \\
\hline Domiciliary NIMV, \% & 4 & 0 & 0 & 7 & 7 & 0.647 \\
\hline $\mathrm{FEV}_{1}, \%$ pred. & $69.2 \pm 22.3$ & $85.2 \pm 22.3$ & $82.1 \pm 20$ & $61.7 \pm 17.4^{b c}$ & $54.3 \pm 15.6^{b c}$ & $\begin{array}{l}< \\
0.001\end{array}$ \\
\hline FVC, \% pred. & $89.6 \pm 18.3$ & $98.6 \pm 17.1$ & $100.4 \pm 20$ & $86 \pm 12.8$ & $77.5 \pm 14.1^{b c}$ & 0.001 \\
\hline $\mathrm{FEV}_{1} / \mathrm{FVC}, \%$ & $64.8 \pm 12.2$ & $72.8 \pm 9.1$ & $70.1 \pm 11.8$ & $59.9 \pm 11.1^{b}$ & $59.6 \pm 11.3^{b}$ & 0.005 \\
\hline IC at rest, \% pred. & $\begin{array}{l}77.5[61.5 ; \\
91.7]\end{array}$ & $76.5[69.2 ; 104.5]$ & $76[57.5 ; 103]$ & $78[63.7 ; 89.5]$ & $81[57 ; 87]$ & 0.977 \\
\hline$V_{T}$ at rest, $L$ & $\begin{array}{l}0.64[0.48 ; \\
0.84]\end{array}$ & $0.61[0.37 ; 0.71]$ & $0.86[0.67 ; 0.95]^{b}$ & $0.50[0.44 ; 0.81]^{c}$ & $0.61[0.54 ; 0.71]^{c}$ & 0.015 \\
\hline RR at rest, breath/min & $\begin{array}{l}17.5[13 ; \\
21.5]\end{array}$ & 18 [16.6; 20.7] & $13[11.8 ; 18]$ & $17[11.7 ; 24]$ & $20[15.9 ; 26]$ & 0.510 \\
\hline
\end{tabular}

Ventilatory efficiency (Vef) and inefficiency (Vin) were defined according to the $\mathrm{V}^{\prime}{ }_{E} / \mathrm{V}^{\prime}{ }_{\mathrm{CO} 2}$ slope $<30$ and $\mathrm{V}_{\mathrm{E}}^{\prime} / \mathrm{V}^{\prime}{ }_{\mathrm{CO} 2}$ slope $\geq 30$, respectively. Patients without and with dynamic hyperinflation $(\mathrm{DH})$ were defined according to the peak-to-rest change of IC $(\triangle \mathrm{IC}, \mathrm{L})>-0.100 \mathrm{~L}$ and $\leq-0.100 \mathrm{~L}$.

Data are shown as number of patients (\%), means \pm SD or medians [1st quartile; 3rd quartile], unless otherwise stated

Abbreviations: BMI body mass index, FFMI fat-free mass index, LTOT long-term oxygen therapy, NIMV non-invasive mechanical ventilation, FEV ${ }_{1}$ forced expiratory

volume at 1 st second, FVC forced vital capacity, $I C$ inspiratory capacity, $V_{T}$ tidal volume, $R R$ respiratory rate

${ }^{a} p$-value calculated between all groups; ${ }^{\mathrm{b}} p$-value $<0.05$ versus patients with Vef and without $\mathrm{DH} ;{ }^{\mathrm{c}} p$-value $<0.05$ versus patients with Vin and without $\mathrm{DH}$

Boldface variables are statistically significants

test for continuous variables. For multiple comparisons, the Bonferroni post-hoc analysis, the ANOVA, and the nonparametric Kruskal-Wallis test were used.

The interrater reliability was evaluated by a two-way random-effects model with mean of $k$ raters and definition of consistency [22]. The intraclass correlation coefficients (ICC) were interpreted by the following scale: ICC values $<0.50$ are indicative of "poor reliability", values between 0.50 and 0.75 indicate "moderate reliability", values between 0.75 and 0.90 indicate "good reliability", and values greater than 0.90 indicate "excellent reliability" [23].

For correlation analysis, the Pearson or Spearman correlation coefficients were used for linear or normally distributed variables and for not linear or not normally distributed variables, respectively.

Receiver operating characteristic (ROC) curves were generated to calculate the area under the curve (AUC) with 95\% confidence interval (CI) and to find the best cut-off with the related sensibility and specificity. Univariate and multivariate regression logistic models (method: Stepwise) were performed to predict the probability to have Vin and $\mathrm{DH}$ (set as dependent variables). Odds ratios (OR) and 95\% CI were calculated. A $p$ value at two tails $<0.05$ was considered significant.

\section{Results}

Our study sample consisted of 52 adult patients with CF, normal-weight, with a wide range of lung function from normal to severe airflow obstruction and a normal-to-mildly reduced maximal exercise capacity. Variables related to spirometry and CPET demonstrated that, in comparison to patients with Vef and without DH and patients with Vin and without DH, patients with Vin and with DH had statistically significant lower values of 
$\mathrm{FEV}_{1} \%$ pred., $\mathrm{FVC} \%$ pred., $\mathrm{FEV}_{1} / \mathrm{FVC} \%$, and lower values in $\mathrm{V}^{\prime}{ }_{\mathrm{O} 2}$ at peak $\mathrm{ml} / \mathrm{kg} / \mathrm{min}$ and workload in watts at peak without reaching statistical significance. Table 1 summarises the results about anthropometric and lung function characteristics and Table 2 CPET-related variables.

The interrater reliability between the two radiologists was "excellent" for T (ICC 0.95; 95\% CI 0.91 to 0.97), B (ICC $0.93 ; 95 \%$ CI 0.88 to 0.96 ), MP (ICC 0.93; 95\% CI 0.88 to 0.96 ), and P (ICC 0.91; 95\% CI 0.84 to 0.95 ), while was "good" for AWT (ICC 0.86; 95\% CI 0.75 to 0.92 ) and AT (ICC 0.81; 95\% CI 0.66 to 0.88 ). Then, the average value of each Brody II score was considered for all analyses. Examples of HRCT metrics according to the Brody II score are provided in Fig. 1, while in Fig. 2 are illustrated for all patients the HRCT variables related to the Brody II scores. Among Vin patients (Fig. 3, bottom left), only AT differed significantly compared to those with Vef. Patients with DH, in comparison to those without DH (Fig. 3, bottom right), had higher values of T, B,

Table 2 CPET-related variables

\begin{tabular}{|c|c|c|c|c|c|c|}
\hline Variables & $\begin{array}{l}\text { Study sample } \\
n=52\end{array}$ & $\begin{array}{l}\text { Patients with Vef and } \\
\text { without DH }\end{array}$ & $\begin{array}{l}\text { Patients with Vin and } \\
\text { without DH }\end{array}$ & $\begin{array}{l}\text { Patients with Vef and } \\
\text { with DH }\end{array}$ & $\begin{array}{l}\text { Patients with Vin and } \\
\text { with } \mathrm{DH}\end{array}$ & $\begin{array}{l}p \\
\text { value } \\
a\end{array}$ \\
\hline $\mathrm{V}_{\mathrm{O} 2}^{\prime}$ at peak, $\mathrm{ml} / \mathrm{kg} / \mathrm{min}$ & $28.1 \pm 8.2$ & $31.0 \pm 7.7$ & $25.8 \pm 7.3$ & $30.7 \pm 9.2$ & $25.7 \pm 7.9$ & 0.180 \\
\hline Workload, watts & $121[97 ; 169]$ & $168[121 ; 216.5]$ & $109[98 ; 146.5]$ & $127.5[94.5 ; 188]$ & $102[88 ; 138]$ & 0.067 \\
\hline$\Delta \mathrm{IC}, \mathrm{L}$ & $\begin{array}{l}-0.19[-0.43 ; \\
0.15]\end{array}$ & $0.24[-0.05 ; 0.37]$ & $0.16[0.08 ; 0.55]$ & $e^{-0.43[-0.54 ;-0.21]^{c}}$ & $e^{-0.38[-0.43 ;-0.26]^{c}}$ & $\begin{array}{l}< \\
0.001\end{array}$ \\
\hline$\Delta V_{T}, L$ & $\begin{array}{l}0.89[0.51 ; \\
1.33]\end{array}$ & $1.34[0.95 ; 1.61]$ & $0.92[0.44 ; 1.24]$ & $0.88[0.57 ; 1.19]^{b}$ & $0.64[0.29 ; 0.89]^{b}$ & 0.039 \\
\hline $\begin{array}{l}\text { RR at peak, breath/ } \\
\text { min }\end{array}$ & $37[32 ; 44]$ & $34[32.1 ; 41.5]$ & $31[28 ; 38.9]$ & $38.8[31.7 ; 42.5]$ & $44[36 ; 51]$ & 0.073 \\
\hline$V_{E}^{\prime} N^{\prime} \mathrm{CO} 2$ at rest & $43.4 \pm 5.9$ & $39.8 \pm 5.1$ & $42.1 \pm 5.0$ & $43.4 \pm 5.3$ & $46.9 \pm 6.2^{b}$ & 0.017 \\
\hline$V_{E}^{\prime} N^{\prime}$ CO2 slope & $29.3 \pm 4.8$ & $25.6 \pm 1.9$ & $33.0 \pm 4.4^{c}$ & $24.9 \pm 2.7^{\mathrm{e}}$ & $32.5 \pm 2.3^{\mathrm{cg}}$ & $\begin{array}{l}< \\
0.001\end{array}$ \\
\hline $\begin{array}{l}V_{E}^{\prime} N^{\prime} \mathrm{CO}_{2} \text { intercept, } \\
L \cdot \mathrm{min}^{-1}\end{array}$ & $\begin{array}{l}3.28[1.95 ; \\
4.33]\end{array}$ & $3.3[2.5 ; 3.6]$ & $0.8[0.2 ; 2.6]^{b}$ & $4[3.2 ; 7.4]^{b d}$ & $3.6[2.6 ; 5]^{d}$ & 0.001 \\
\hline $\begin{array}{l}\mathrm{O}_{2} \text { pulse at rest, } \mathrm{mL} / \\
\text { beat/min }\end{array}$ & $3.2[2.3 ; 3.9]$ & $3.3[2.1 ; 4.5]$ & $3.3[2.1 ; 3.9]$ & $3[2.5 ; 3.9]$ & $3.3[2.3 ; 3.9]$ & 0.948 \\
\hline $\begin{array}{l}\Delta \mathrm{O}_{2} \text { pulse, } \mathrm{mL} / \text { beat/ } \\
\text { min }\end{array}$ & $7.0 \pm 2.6$ & $8.8 \pm 2.7$ & $6.0 \pm 2.1^{b}$ & $7.9 \pm 3.0$ & $5.9 \pm 1.5^{b}$ & 0.008 \\
\hline$\Delta P_{\mathrm{ETCO} 2}$ & $6[4 ; 9]$ & $6.5[4.7 ; 8]$ & $3[0.5 ; 6]$ & $10[6.7 ; 14]^{\mathrm{be} \mathrm{e}}$ & $6[3 ; 7]^{f}$ & 0.001 \\
\hline$H R_{\text {recovery }}$ & $23[15.2 ; 28]$ & $25[21.7 ; 31]$ & $23[15.5 ; 27.5]$ & 20.5 [14.2; 24.5] & $23[13 ; 29]$ & 0.261 \\
\hline $\mathrm{HR} / \mathrm{N}_{\mathrm{O} 2}$ & $56[46 ; 65.7]$ & $47.5[41.7 ; 59]$ & $59[47.5 ; 74]$ & $50[42 ; 64.2]$ & $62[52 ; 73]$ & 0.122 \\
\hline DP reserve & $\begin{array}{l}15,251.1 \pm \\
4192.6\end{array}$ & $15,387.0 \pm 5090.4$ & $14,966.5 \pm 3391.4$ & $15,063.2 \pm 4187.2$ & $15,582.7 \pm 4582.2$ & 0.980 \\
\hline DP reserve/Workload & $123.8 \pm 35.8$ & $97.1 \pm 36.1$ & $129.9 \pm 36.3$ & $117.4 \pm 27.9$ & $142.3 \pm 31.9^{b}$ & 0.011 \\
\hline $\mathrm{SpO}_{2}$ at rest, $\%$ & $96.7 \pm 1.7$ & $97.3 \pm 1.9$ & $97.5 \pm 1.3$ & $96.4 \pm 1.8$ & $95.9 \pm 1.7$ & 0.079 \\
\hline$\Delta \mathrm{SpO}_{2}, \%$ & $-2.0 \pm 3.3$ & $-0.6 \pm 2.5$ & $-1.1 \pm 2.7$ & $-3.9 \pm 3.8$ & $-2.0 \pm 3.4$ & 0.065 \\
\hline Peak dyspnea & $\begin{array}{l}0.51[0.39 ; \\
0.77]\end{array}$ & $0.43[0.25 ; 0.62]$ & $0.55[0.44 ; 0.73]$ & $0.52[0.36 ; 0.88]$ & $0.57[0.45 ; 0.95]$ & 0.384 \\
\hline Peak fatigue & $\begin{array}{l}0.65[0.45 ; \\
0.82]\end{array}$ & $0.47[0.38 ; 0.77]$ & $0.74[0.60 ; 0.88]$ & $0.60[0.34 ; 0.77]$ & $0.71[0.57 ; 0.91]$ & 0.198 \\
\hline
\end{tabular}

Data are shown as number of patients (\%), means \pm SD or medians [1st quartile; 3rd quartile], unless otherwise stated Variables with $\Delta$ were calculated as peak-to-rest changes

Abbreviations: $V_{\mathrm{O} 2}^{\prime}$ oxygen uptake, $I C$ inspiratory capacity, $V_{T}$ tidal volume, $R R$ respiratory rate, $V_{E}^{\prime}$ minute ventilation, $V_{C O 2}^{\prime}$ carbon dioxide output, $P_{E T C O 2}$ end-tidal pressure of $\mathrm{CO}_{2}, \mathrm{HR}$ heart rate, $\mathrm{DP}$ double product, $\mathrm{SpO}_{2}$ oxygen saturation

Peak dyspnea and peak fatigue were described as visual analogic scale (VAS) with 0-100 score and peak workload ratio

${ }^{a} p$-value calculated between all groups

${ }^{\mathrm{b}} p$-value $<0.05$ versus patients with Vef and without $\mathrm{DH}$

$c^{c} p$-value $<0.001$ versus patients with Vef and without $\mathrm{DH}$

${ }^{d} p$-value $<0.05$ versus patients with $\mathrm{Vin}$ and without $\mathrm{DH}$

${ }^{e} p$-value $<0.001$ versus patients with Vin and without $\mathrm{DH}$

${ }^{f} p$-value $<0.05$ versus patients with Vef and with $\mathrm{DH}$

${ }^{g} p$-value $<0.001$ versus patients with Vef and with $\mathrm{DH}$

Boldface variables are statistically significants 


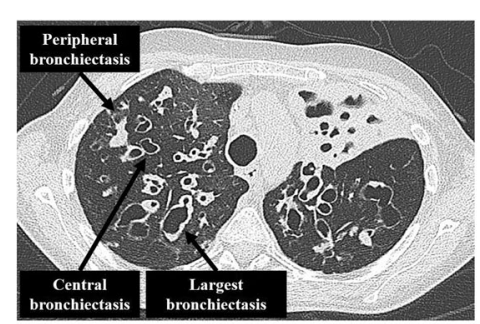

Total atelectasis of the left upper lobe

Extent of atelectasis $>67 \%$ (HRCT score 3$)$

Bronchiectasis in right upper lobe

- Extent of bronchiectasis in central lung: $>67 \%$ (HRCT score 3)

- Extent of bronchiectasis in peripheral lung: $33 \%$ to $67 \%$ (HRCT score 2 )

- Size of largest dilated bronchus: BLD/AOD: > 3 (HRCT score 3)

- Average size of dilated bronchi: BLD/AOD: 2 to 3 (HRCT score 2)

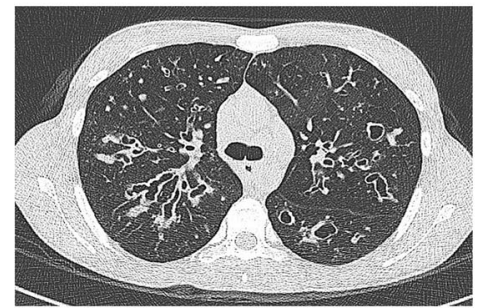

Airway wall thickening in right upper lobe

- Extent of bronchial wall thickening in central lung: $33 \%$ to $67 \%$ (HRCT score 2)

- Extent of bronchial wall thickening in the peripheral lung: $<33 \%$ (HRCT score 1)

- Severity Score BWT/AOD : 0.5 to 1 (HRCT score 2)

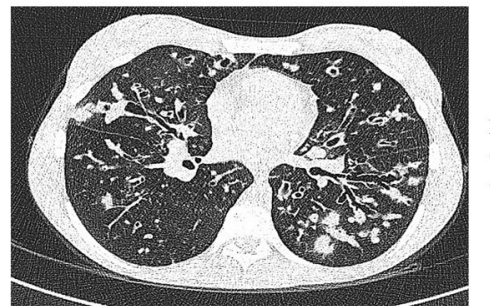

Mucous plugging in the left lower lobe

- Extent in large airways: > $67 \%$ (HRCT score 3 )

- Extent in small airways: $33 \%$ to $67 \%$ (HRCT score 2 )

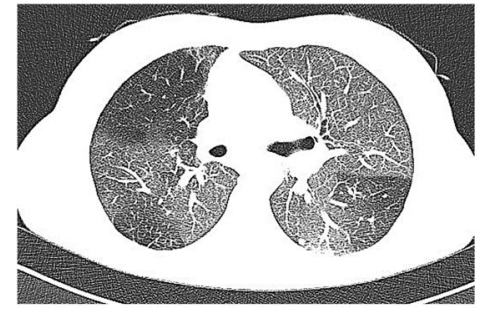

Air trapping in the right middle lobe

- Extent: $33 \%$ to $67 \%$ (HRCT score 2)

- Pattern: Segmental

Fig. 1 Example of HRCT metrics according to the Brody II scoring system. Abbreviations: BLD indicates bronchial lumen diameter; AOD, adjacent pulmonary artery outer diameter; BWT, bronchial wall thickening

AWT, and MP, respectively. Patients with Vin and with $\mathrm{DH}$ had higher values of T, B and AT compared to other groups (Fig. 3, top).

Significant correlations were found between $\mathrm{V}_{\mathrm{E}}{ }_{\mathrm{E}} / \mathrm{V}^{\prime}{ }_{\mathrm{CO} 2}$ intercept and $\mathrm{V}_{\mathrm{E}}^{\prime} / \mathrm{V}^{\prime}{ }_{\mathrm{CO} 2}$ slope and between $\mathrm{V}_{\mathrm{E}}^{\prime} / \mathrm{V}^{\prime} \mathrm{CO} 2$ intercept and $\Delta$ IC. No correlation, however, was found between $\mathrm{V}_{\mathrm{E}}{ }^{\prime} / \mathrm{V}^{\prime}{ }_{\mathrm{CO} 2}$ slope and $\Delta \mathrm{IC}$ (Fig. 4). Multiple comparisons between patient subgroups (Fig. 5) showed that $\mathrm{V}_{\mathrm{E}}^{\prime} /$ $\mathrm{V}^{\prime} \mathrm{CO} 2$ intercept was significantly higher among patients with Vef and with DH compared to those with Vef and without DH and those with Vin and without DH. Moreover, $\mathrm{V}_{\mathrm{E}}{ }_{\mathrm{V}} / \mathrm{V}_{\mathrm{CO} 2}$ intercept was significantly lower in patients with Vin and without DH than those with Vef and without DH and those with Vin and with DH.

Regression analysis (Table 3 ) showed that AT was the only independent predictor of Vin, whilst T, B, AWT and MP were significant predictors of the development of $\mathrm{DH}$.

\section{Discussion}

Our study in adult patients with CF allows us to highlight two main findings: 1) there is no correlation between Vin and DH and variables derived from spirometry and CPET seem to be complementary and specific to one condition rather another and 2) Brody II scores at HRCT are able to discriminate and predict Vin (AT) and DH (T, B, AWT and MP).

\section{Ventilatory response to exercise in CF patients}

There are very few data about the ventilatory response to exercise in adult CF patients. In a retrospective study on $102 \mathrm{CF}$ patients with mild-to-moderate lung disease, the authors reported that $\mathrm{V}_{\mathrm{E}} / \mathrm{V}_{\mathrm{CO} 2}$ at peak was not related to airflow obstruction but to the $\mathrm{V}_{\mathrm{O} 2}$ at peak [5]. High values of $\mathrm{V}_{\mathrm{E}} / \mathrm{V}_{\mathrm{CO} 2}$ slope identify greater dead space $\left(\mathrm{V}_{\mathrm{D}}\right)$ due to more extensive emphysema and/or high pulmonary vascular pressures, poorer cardiac performance, 


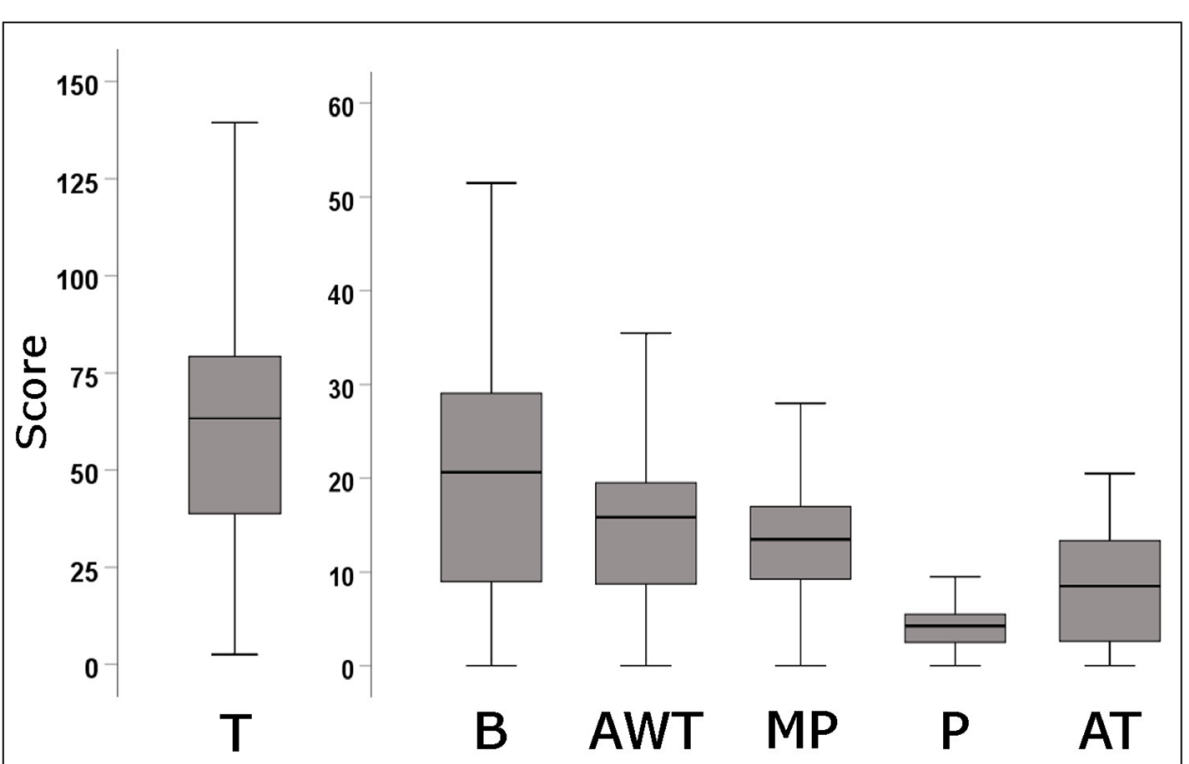

Fig. 2 Boxplots of HRCT variables in study sample. Abbreviations: T indicates total score; B, bronchiectasis score; AWT, airways wall thickening score; MP, mucous plugging score; P, parenchyma score; AT, air trapping score

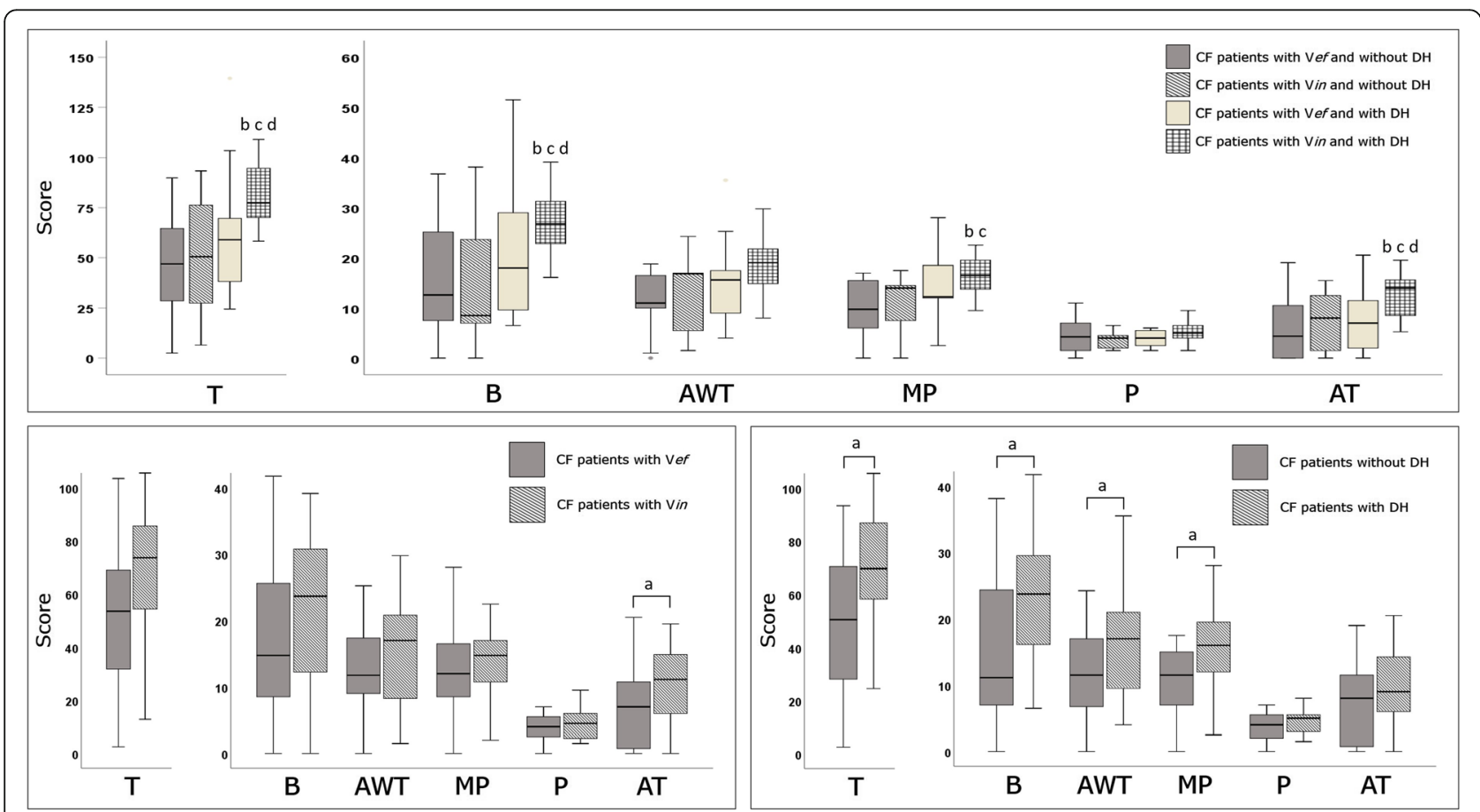

Fig. 3 Boxplots of HRCT variables according to the presence of associated ventilatory efficiency/inefficiency and/or presence or absence of dynamic hyperinflation ((top), ventilatory efficiency/inefficiency only (bottom left), and presence/absence of dynamic hyperinflation only (bottom right). Abbreviations: Vef and Vin indicates ventilator efficiency and inefficiency, respectively; DH, dynamic hyperinflation; T, total score; $\mathrm{B}$, bronchiectasis score; AWT, airways wall thickening score; MP, mucous plugging score; $\mathrm{P}$, parenchyma score; AT, air trapping score. ${ }^{a} p$ value calculated between groups; ${ }^{\mathrm{b}} p<0.05$ versus patients with Vef and without $\mathrm{DH} ;{ }^{\mathrm{c}} p<0.05$ versus patients with $\mathrm{Vin}$ and without $\mathrm{DH}$; ${ }^{\mathrm{d}} p$ value $<$ 0.05 versus patients with Vef and with $\mathrm{DH}$ 

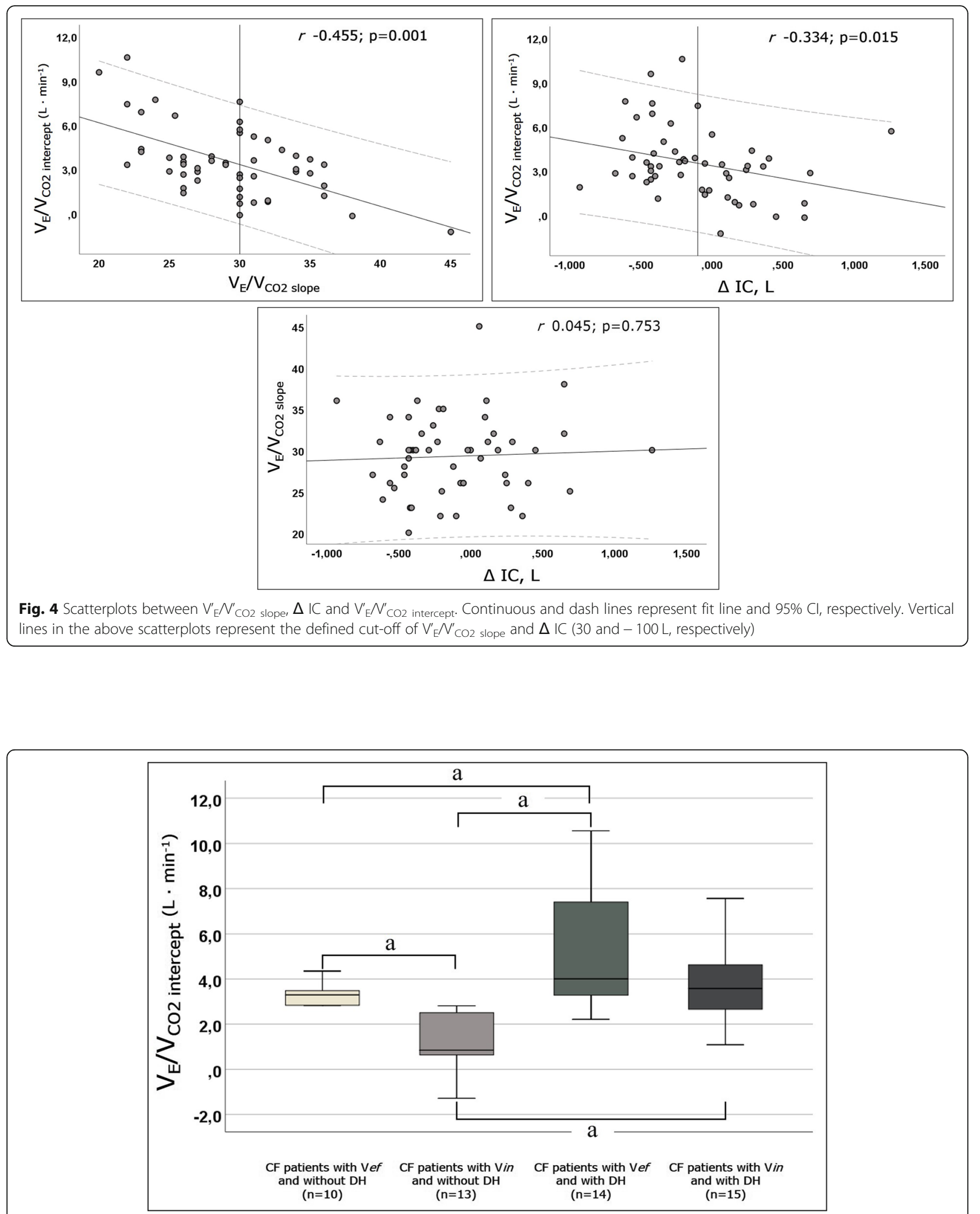

Fig. 5 Boxplots of $V^{\prime} E V^{\prime}{ }_{C O 2}$ intercept according to the presence of associated ventilatory efficiency/inefficiency and/or presence or absence of dynamic hyperinflation. Abbreviations: Vef and Vin indicates ventilator efficiency and inefficiency, respectively; DH, dynamic hyperinflation. a $p<0.05$ 
Table 3 Receiver operating characteristic (ROC) variables and univariate regression predicting the probability to have exercise ventilatory inefficiency or dynamic hyperinflation

\begin{tabular}{|c|c|c|c|c|c|c|c|c|}
\hline \multirow[t]{2}{*}{ Variables } & \multicolumn{5}{|c|}{ ROC variables } & \multicolumn{3}{|c|}{ Univariate regression } \\
\hline & Cut-off & AUC & $95 \% \mathrm{Cl}$ & Sensitivity & Specificity & $\overline{\mathrm{OR}}$ & $95 \% \mathrm{Cl}$ & $p$ value \\
\hline \multicolumn{9}{|c|}{ Dependent variable: Ventilatory inefficiency } \\
\hline AT (score) & 7.9 & 0.682 & 0.535 to 0.829 & 0.714 & 0.583 & 3.50 & 1.10 to 11.09 & 0.033 \\
\hline \multicolumn{9}{|c|}{ Dependent variable: Dynamic hyperinflation } \\
\hline $\mathrm{T}$ (score) & 53.6 & 0.707 & 0.564 to 0.849 & 0.793 & 0.565 & 4.98 & 1.47 to 16.86 & 0.010 \\
\hline B (score) & 16.1 & 0.699 & 0.550 to 0.848 & 0.759 & 0.608 & 4.88 & 1.48 to 16.12 & 0.009 \\
\hline AWT (score) & 13.0 & 0.663 & 0.514 to 0.811 & 0.724 & 0.565 & 3.41 & 1.07 to 10.87 & 0.038 \\
\hline MP (score) & 11.7 & 0.711 & 0.570 to 0.851 & 0.793 & 0.521 & 4.18 & 1.24 to 14.09 & 0.021 \\
\hline
\end{tabular}

Abbreviations: $A T$ indicates air trapping score, $T$ total score, $B$ bronchiectasis score, $A W T$ airways wall thickening score, MP mucous plugging score Boldface variables are statistically significants

higher sympathetic drive, worse exertional hypoxemia and greater ergoreceptor stimulation [18]. Indeed, in a sample of CF children undergoing sub-maximal constant work rate exercise testing, the arterial partial pressure of carbon dioxide $\left(\mathrm{PaCO}_{2}\right)$ levels were significantly related to alveolar ventilation rather than $\mathrm{V}_{\mathrm{E}}$; this denotes the leading role of physiologic $V_{D}$ in the quantitative determination of ventilatory response to exercise [24].

In our cohort, data about the relationship between $\mathrm{DH}$ and lung function impairment at rest are in line with Stevens et al. [6]. Surprisingly, we did not observe differences in term of exercise tolerance [6]; however, patients with DH and Vin had a tendency to show a poorer exercise tolerance (Table 2). It is of note that in COPD patients, $\mathrm{V}_{\mathrm{E}} / \mathrm{V}_{\mathrm{CO} 2}$ measurements may explain exercise intolerance, particularly in milder and in symptomatic patients with preserved $\mathrm{FEV}_{1}$ [25], since an increased $V_{D}$ may occur [25].

\section{The value of HRCT metrics in Vin and DH}

HRCT scores and CPET-variables have been often used separately to predict future outcomes in CF patients, such as early structural alterations [3] or disease progression $[10,11]$. However, in adult CF patients no studies looked for determinants of two exercise-induced functional scenario (presence of Vin and DH) using HRCT scores.

Air trapping at HCRT is an important marker of distal airways disease in children with CF [26] and in COPD patients [27]. Using a modified Bhalla scoring system, a retrospective study [28] demonstrated that HRCT abnormalities were more sensible than lung function (evaluated only by $\mathrm{FEV}_{1}$ ) to detect disease decline of adult $\mathrm{CF}$ patients; notably, patients with air trapping and moderate-to-severely impaired lung function had more rapid rate of deterioration [28]. Moreover, in children with $\mathrm{CF}$, air trapping demonstrated a significant relationship with non-invasive measures of ventilation inhomogeneity, such as the lung clearance index (LCI) [29].
These aspects are in line with our regression analysis, in which AT score independently increases the probability to have Vin which, at least for COPD patients, may define a series of worse disease-related features [18]. Similarly, HRCT metrics on emphysema measured by low attenuation areas (LAA\%) - that conceptually may be seen as a surrogate of AT - were shown to significantly explain $\mathrm{V}_{\mathrm{E}} / \mathrm{V}_{\mathrm{CO} 2 \text { slope }}$ in COPD patients in a multivariate adjusted linear regression model [12].

MP, secondary to the basic ion-transport defect of the disease, represents a recognized HRCT hallmark of disease [30] and, together with perfusion abnormalities seems to play a relevant role in exacerbation [31]. Based on our results, it may also have a potentially reversible role on $\mathrm{DH}$.

\section{The $\mathrm{V}_{\mathrm{E}}{ }_{\mathrm{E}} / \mathrm{V}^{\prime}{ }_{\mathrm{CO}}$ intercept in CF patients}

The relationship between $\mathrm{V}_{\mathrm{E}}^{\prime}$ and $\mathrm{V}_{\mathrm{CO} 2}^{\prime}$ - when $\mathrm{V}_{\mathrm{CO} 2}$ is equal to zero - represents the $\mathrm{V}_{\mathrm{E}}^{\prime} / \mathrm{V}^{\prime} \mathrm{CO}$ intercept [18]. In normal subjects, $\mathrm{V}_{\mathrm{E}}^{\prime} / \mathrm{V}_{\mathrm{CO} 2}{ }_{\mathrm{C}}$ intercept is a small positive value $\left(<3 \mathrm{~L} \cdot \mathrm{min}^{-1}\right)$ [32]. In COPD patients, $\mathrm{V}_{\mathrm{E}}^{\prime} / \mathrm{V}^{\prime} \mathrm{CO} 2$ intercept is related to greater $\mathrm{DH}[18]$ and it is associated with exertional dyspnea [18].

In our CF patients, $\mathrm{V}_{\mathrm{E}}^{\prime} / \mathrm{V}^{\prime} \mathrm{CO} 2$ intercept values lead us to some considerations. Among the whole study group, the median value was high (3.28) and, in particular, it was higher in patients with $\mathrm{Vef}\left(\mathrm{V}_{\mathrm{E}}^{\prime} / \mathrm{V}^{\prime} \mathrm{CO}_{\text {2 slope }}<30\right)$ and with $\mathrm{DH}$. As shown for COPD patients [18], a high $\mathrm{V}_{\mathrm{E}}^{\prime} / \mathrm{V}_{\mathrm{CO} 2}$ intercept is a necessary compromise for the progressive mechanical respiratory constraints, increased $V_{D}$ and reduced $\mathrm{V}_{\mathrm{E}}^{\prime} / \mathrm{V}_{\mathrm{CO} 2}^{\prime}$ slope. Notably, it is proved that $\mathrm{V}_{\mathrm{E}}^{\prime} /$ $\mathrm{V}^{\prime} \mathrm{CO} 2$ intercept reflects some aspects about the $\mathrm{V}_{\mathrm{D}}$ [33]. The increased $V_{D}$ and ventilation inhomogeneity [29] in our CF patients may explain the increased value of $V_{E}^{\prime} /$ $\mathrm{V}^{\prime} \mathrm{CO} 2$ intercept in $\mathrm{DH}$ patients. Then, in this context it is plausible that $\mathrm{V}_{\mathrm{E}}, \mathrm{V}_{\mathrm{CO} 2}$ intercept correlates with both $\mathrm{V}_{\mathrm{E}}^{\prime} /$ $\mathrm{V}^{\prime} \mathrm{CO} 2$ slope and $\triangle \mathrm{IC}$. Because each condition (Vin and $\mathrm{DH}$ ) influences, in different ways, the $\mathrm{V}_{\mathrm{E}}^{\prime} / \mathrm{V}_{\mathrm{CO} 2}^{\prime}$ intercept 
(Table 2), the level of this parameter does not increase if the two conditions coexist (Fig. 5).

\section{Strength and limitations of the study}

Although our study has some important points of strength (originality because for the first time the exercise-induced ventilatory response was considered and the wide cohort of adult CF, in which all participant performed both HRCT and CPET) we need to report some limitations. First, our study concerns data collected in a single center in Italy, in adult CF with a wide range of lung function from normal to severe airflow obstruction and a relatively well-conserved maximal exercise capacity. The considerations derived from our analyses cannot be translated into patients with different functional and physical characteristics. Secondly, data about ATs have been collected only during the inspiration phase. Although in CF a pilot study demonstrated a very good agreement between HRCT scores from end-expiratory and end-inspiratory scans [34], we cannot be sure that the execution of the end-expiratory phase scans could have changed our findings.

\section{Conclusion}

In summary, our prospective study performed in a cohort of adult patients with CF showed the values of HRCT metrics as determinants of Vin (AT) and DH (T, $\mathrm{B}, \mathrm{AWT}$ and MP). Moreover, we highlighted in CF patients the functional and clinical potential role of Vin and $\mathrm{DH}$. We believe that in the future these aspects should be considered when exercise tolerance is assessed, such as for COPD patients. The comprehensive scenario for CF patients could be more interesting.

\section{Abbreviations}

AOD: adjacent pulmonary artery outer diameter; AUC: area under the curve; BLD: bronchial lumen diameter; BMl: body mass index; BWT: bronchial wall thickening; CF: cystic fibrosis; Cl: confidence interval; CPET: cardio-pulmonary

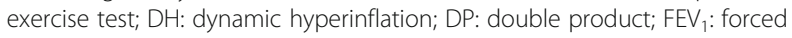
expiratory volume at 1st second; FVC: forced vital capacity; HRCT: highresolution computed tomography; IC: inspiratory capacity; ICC: intraclass correlation coefficients; $\mathrm{O}_{2}$ pulse: oxygen pulse; $\mathrm{P}_{\mathrm{ETCO}}$ : end-tidal pressure of $\mathrm{CO}_{2}$; $\mathrm{ROC}$ : receiver operating characteristic; RR: respiratory rate; $\mathrm{SpO}_{2}$ : oxygen saturation; TLC: total lung capacity; VAS: visual analogic scale; $V_{\mathrm{CO}_{2}}$ : carbon dioxide production; $V_{E}$ : minute ventilation; Vef: ventilatory efficiency; $\checkmark$ in: ventilatory inefficiency; $V_{\mathrm{T}}$ : tidal volume

\section{Acknowledgements}

None.

\section{Funding}

This work was not supported by any financial source.

\section{Availability of data and materials}

The datasets used and/or analysed during the current study are available from the corresponding author on reasonable request.

\section{Authors' contributions}

$E C, M D P, N S, P P, A C, G P$ contributed to conception and design of the work $E T, S L, F L, P T, P P, A I, C L$ contributed to acquisition, analysis or interpretation of data for the work. EC, MDP, NS, PP, AC, GP contributed to drafting the article or revising it critically for important intellectual content. EC, AC: Final approval of the version.

Ethics approval and consent to participate

The ethical committee of the University Hospital of Parma approved the protocol (approval number: 200084; 07 June 2013).

\section{Consent for publication}

Not applicable.

\section{Competing interests}

The authors declare that they have no competing interests

\section{Publisher's Note}

Springer Nature remains neutral with regard to jurisdictional claims in published maps and institutional affiliations.

\section{Author details}

${ }^{1}$ Department of Medicine and Surgery, Respiratory Disease and Lung Function Unit, University of Parma, Via Rasori 10, 43126 Parma, Italy. ${ }^{2}$ Section of Radiology, Unit of Surgical Sciences, Department of Medicine and Surgery, University of Parma, Parma, Italy. ${ }^{3}$ Cystic Fibrosis Unit, University Hospital of Parma, Parma, Italy. ${ }^{4}$ Department of Public Health and Infectious Diseases, Sapienza University of Rome, Rome, Italy.

Received: 5 December 2018 Accepted: 7 April 2019

Published online: 24 April 2019

References

1. Gibson RL, Burns JL, Ramsey BW. Pathophysiology and management of pulmonary infections in cystic fibrosis. Am J Respir Crit Care Med. 2003; 168(8):918-51.

2. Tiddens HA. Detecting early structural lung damage in cystic fibrosis. Pediatr Pulmonol. 2002;34(3):228-31

3. Hatziagorou E, Kampouras A, Avramidou V, et al. Exercise responses are related to structural lung damage in CF pulmonary disease. Pediatr Pulmonol. 2016:51(9):914-20.

4. Bongers $B C$, Werkman MS, Takken T, Hulzebos EH. Ventilatory response to exercise in adolescents with cystic fibrosis and mild-to-moderate airway obstruction. Springerplus. 2014;3:696

5. Pastré J, Prévotat A, Tardif C, Langlois C, Duhamel A, Wallaert B. Determinants of exercise capacity in cystic fibrosis patients with mild-tomoderate lung disease. BMC Pulm Med. 2014;14:74.

6. Stevens D, Stephenson A, Faughnan ME, Leek E, Tullis E. Prognostic relevance of dynamic hyperinflation during cardiopulmonary exercise testing in adult patients with cystic fibrosis. J Cyst Fibros. 2013;12(6):655-61.

7. Brody AS, Klein JS, Molina PL, Quan J, Bean JA, Wilmott RW. High-resolution computed tomography in young patients with cystic fibrosis: distribution of abnormalities and correlation with pulmonary function tests. J Pediatr. 2004; 145(1):32-8.

8. Davis SD, Fordham LA, Brody AS, et al. Computed tomography reflects lower airway inflammation and tracks changes in early cystic fibrosis. Am J Respir Crit Care Med. 2007;175(9):943-50.

9. Weber K, Paolini M, Schmitz M, et al. Cystic fibrosis in adults: short-term and long-term reproducibility of the Brody score for lung morphology in lowdose MDCT scans. Rofo. 2014;186(1):54-60.

10. Sanders DB, Li Z, Brody AS, Farrell PM. Chest computed tomography scores of severity are associated with future lung disease progression in children with cystic fibrosis. Am J Respir Crit Care Med. 2011:184(7):816-21.

11. Sanders DB, Li Z, Brody AS. Chest computed tomography predicts the frequency of pulmonary exacerbations in children with cystic fibrosis. Ann Am Thorac Soc. 2015;12(1):64-9.

12. Crisafulli E, Alfieri V, Silva M, et al. Relationships between emphysema and airways metrics at high-resolution computed tomography (HRCT) and ventilatory response to exercise in mild to moderate COPD patients. Respir Med. 2016:117:207-14. https://doi.org/10.1016/j.rmed.2016.06.016.

13. Farrell PM, White TB, Ren CL, et al. Diagnosis of Cystic Fibrosis: Consensus Guidelines from the Cystic Fibrosis Foundation. J Pediatr. 2017:181S:S4-S15. e1. https://doi.org/10.1016/j.jpeds.2016.09.064.

14. Miller MR, Hankinson J, Brusasco V, et al. ATS/ERS task force. Standardisation of spirometry. Eur Respir J. 2005;26(2):319-38. 
15. Wanger J, Clausen $\mathrm{J} \mathrm{L}$, Coates A, et al. Standardisation of the measurement of lung volumes. Eur Respir J. 2005;26(3):511-22.

16. American Thoracic Society; American College of Chest Physicians. ATS/ACCP statement on cardiopulmonary exercise testing. Am J Respir Crit Care Med. 2003;167(2):211-77.

17. Puente-Maestu L, Palange P, Casaburi R, et al. Use of exercise testing in the evaluation of interventional efficacy: an official ERS statement. Eur Respir J. 2016;47(2):429-60. https://doi.org/10.1183/13993003.00745-2015.

18. Neder JA, Berton DC, Arbex FF, et al. Physiological and clinical relevance of exercise ventilatory efficiency in COPD. Eur Respir J. 2017;49(3). https://doi. org/10.1183/13993003.02036-2016.

19. Stubbing DG, Pengelly LD, Morse JL, Jones NL. Pulmonary mechanics during exercise in subjects with chronic airflow obstruction. J Appl Physiol. 1980;49:511-5

20. Regnis JA, Alison JA, Henke KG, Donnelly PM, Bye PT. Changes in endexpiratory lung volume during exercise in cystic fibrosis relate to severity of lung disease. Am Rev Respir Dis. 1991;144:507-12.

21. Gobel FL, Norstrom LA, Nelson RR, Jorgensen CR, Wang Y. The rate-pressure product as an index of myocardial oxygen consumption during exercise in patients with angina pectoris. Circulation. 1978;57(3):549-56.

22. McGraw KO, Wong SP. Forming inferences about some intraclass correlation coefficients. Psychol Methods. 1996;1:30-46.

23. Koo TK, Li MY. A guideline of selecting and reporting Intraclass correlation coefficients for reliability research. J Chiropr Med. 2016;15(2):155-63. https:// doi.org/10.1016/j.jcm.2016.02.012.

24. Pianosi P, Wolstein R. Carbon dioxide chemosensitivity and exercise ventilation in healthy children and in children with cystic fibrosis. Pediatr Res. 1996:40(3):508-13.

25. Elbehairy AF, Ciavaglia CE, Webb KA, et al. Canadian respiratory research network. Pulmonary gas exchange abnormalities in mild chronic obstructive pulmonary disease. Implications for dyspnea and exercise intolerance. Am J Respir Crit Care Med. 2015;191(12):1384-94.

26. Bonnel AS, Song SM, Kesavarju K, et al. Quantitative air-trapping analysis in children with mild cystic fibrosis lung disease. Pediatr Pulmonol. 2004;38(5): 396-405.

27. Lee SM, Seo JB, Lee SM, Kim N, Oh SY, Oh YM. Optimal threshold of subtraction method for quantification of air-trapping on coregistered CT in COPD patients. Eur Radiol. 2016;26(7):2184-92.

28. Judge EP, Dodd JD, Masterson JB, Gallagher CG. Pulmonary abnormalities on high-resolution CT demonstrate more rapid decline than FEV1 in adults with cystic fibrosis. Chest. 2006;130(5):1424-32

29. Owens CM, Aurora P, Stanojevic S, et al. London cystic fibrosis collaboration. Lung clearance index and HRCT are complementary markers of lung abnormalities in young children with CF. Thorax. 2011;66(6):481-8.

30. Wielpütz $M O$, Eichinger $M$, Biederer J, et al. Imaging of cystic fibrosis lung disease and clinical interpretation. Rofo. 2016 Sep;188(9):834-45.

31. Wielpütz MO, Puderbach M, Kopp-Schneider A, et al. Magnetic resonance imaging detects changes in structure and perfusion, and response to therapy in early cystic fibrosis lung disease. Am J Respir Crit Care Med. 2014; 189:956-65.

32. Sun XG, Hansen JE, Garatachea N, Storer TW, Wasserman K. Ventilatory efficiency during exercise in healthy subjects. Am J Respir Crit Care Med. 2002;166(11):1443-8

33. Gargiulo P, Apostolo A, Perrone-Filardi P, Sciomer S, Palange P, Agostoni P. A non invasive estimate of dead space ventilation from exercise measurements. PLoS One. 2014;9(1):e87395.

34. Loeve $M$, Lequin $M H$, de Bruijne $M$, et al. Cystic fibrosis: are volumetric ultralow-dose expiratory $\mathrm{CT}$ scans sufficient for monitoring related lung disease? Radiology. 2009;253(1):223-9. https://doi.org/10.1148/radiol.2532090306.

Ready to submit your research? Choose BMC and benefit from:

- fast, convenient online submission

- thorough peer review by experienced researchers in your field

- rapid publication on acceptance

- support for research data, including large and complex data types

- gold Open Access which fosters wider collaboration and increased citations

- maximum visibility for your research: over $100 \mathrm{M}$ website views per year

At BMC, research is always in progress.

Learn more biomedcentral.com/submissions 